\title{
Rheumatology in Poland
}

\author{
Maria Maślińska' ${ }^{1} \cdot$ Tomasz Dobrzyński ${ }^{1,2}$ (B) Brygida Kwiatkowska ${ }^{1}(\mathbb{D}$
}

Received: 17 January 2019 / Accepted: 15 March 2019 / Published online: 28 March 2019

(c) The Author(s) 2019

\begin{abstract}
The aim of this article is to present the current state of rheumatology in Poland, including the scientific and clinical activity and essential aspects of Polish rheumatic patients' treatment. PubMed, Scopus and Web of Science databases were searched for main keywords: "rheumat*" and affiliation with Poland. Statistical data were obtained from the Central Statistical Office, the National Health Fund and the Polish Chamber of Physicians and Dentists, while the public information from the Polish Society for Rheumatology, the Ministry of Health and the Ministry of Science and Higher Education. Databases of the World Health Organization, the Organization for Economic Co-operation and Development and the European Statistical Office (Eurostat) were used. Most Polish rheumatologists work in large urban agglomerations in the Mazovian, Malopolskie and Silesian Voivodeships. The rheumatologic infrastructure includes 1713 working rheumatologists $(>30 \%$ exceeding the age of 60 years), 2301 hospital beds, 2279 outpatient clinics and 955 private practices. Poland's state funding is relatively limited, this problem being addressed by health officials with special treatment programs for biological drugs. The Eurostat data indicate, that in Poland, like in the majority of EU Member States, there's a tendency of specialist/general practitioner ratio rising. The number of scientific publications by Polish rheumatologists has steadily increased in recent years. Poland's rheumatology has made an enormous progress at all levels of functioning in recent decades. The EULAR recommendations are mostly incorporated into the Polish health system, leaving still room for its further improvement in the fields of financing, therapy and education.
\end{abstract}

Keywords Rheumatology $\cdot$ Poland $\cdot$ Rheumatological care $\cdot$ Healthcare system $\cdot$ Publications $\cdot$ Perspectives

\begin{tabular}{|c|c|}
\hline \multicolumn{2}{|c|}{ Abbreviations } \\
\hline GUS & Central Statistical Office/Główny Urząd \\
\hline & Statystyczny \\
\hline DAiS & Analysis and Strategy Department Data \\
\hline EULAR & European League against Rheumatism \\
\hline NIL & $\begin{array}{l}\text { The Polish Chamber of Physicians and Den- } \\
\text { tists/Naczelna Izba Lekarska }\end{array}$ \\
\hline NIGRiR & $\begin{array}{l}\text { National Institute of Geriatrics, Rheumatology } \\
\text { and Rehabilitation }\end{array}$ \\
\hline NFZ & $\begin{array}{l}\text { National Health Fund/Narodowy Fundusz } \\
\text { Zdrowia }\end{array}$ \\
\hline
\end{tabular}

Maria Maślińska

maslinskam@gmail.com

1 National Institute of Geriatrics, Rheumatology and Rehabilitation, Warsaw, Poland

2 Institute of Applied Social Science, University of Warsaw, Warsaw, Poland

$\begin{array}{ll}\text { SMPT } & \text { Therapeutic Program Monitoring Sys- } \\ & \text { tem/System Monitorowania Programów } \\ & \text { Terapeutycznych } \\ \text { WHO } & \text { World Health Organization }\end{array}$

\section{Introduction}

Rheumatology in Poland began to take its present shape in 1948 with the opening of the first rheumatological outpatient clinic by doctor (and later professor) Eleonora Reicher in her private apartment at Polna street among the ruins of post-war Warsaw. The continued effort of Prof. Reicher led to the establishment of the Institute of Rheumatology that same year. Since then, many rheumatological hospital centers and outpatient clinics have been established in Poland. A system of sanatoriums focused on a broadly understood rehabilitation of patients with rheumatic diseases, with the use of balneology, has also been set up. According to the Polish Chamber of Physicians and Dentists (Naczelna Izba Lekarska-NIL) there are currently 1713 rheumatologists 
working in Poland [1]. After the fall of communism, along with the opening of Poland's borders, the flow of scientific information broadened, professional and scientific contacts with the medical world became easier and more common. Along with the improvement of country's economic standing, the financing of modern medical procedures increased, making them more available. The European League Against Rheumatism (EULAR) recommendations were (and still are) gradually implemented into national (Polish) recommendations. Therapeutic programs were created by the National Health Fund (Narodowy Fundusz Zdrowia-NFZ) to finance biological therapies, with patient inclusion criteria modified to accommodate proper recommendations of the EULAR. Despite the ongoing financial difficulties, a still increasing number of patients with an active disease is being treated with biological agents.

Right from its beginning, the Polish rheumatological community contributed to the scientific progress in medicine. Polish rheumatologists published articles in numerous scientific journals and took part in scientific congresses all over the world. Recognizing the need to create a scientific journal of their own, Polish rheumatologists started "Reumatologia" ("Rheumatology" in English) journal, presently a bi-monthly published entirely in English, indexed in many international databases, including Scopus and Clarivate. In later years, educational Polish-language journals concerning rheumatology were also established, targeting locally Polish readers.

The following databases: MEDLINE, Scopus and Web of Science (WoS) were searched for articles with main keyword: "rheumat*" included in "title" and "topic" fields (in WoS the "abstract" field was also included in the search, due to the structure of this database) and with Poland stated as the country of an affiliation.

This method allows selecting publications both related to rheumatic diseases directly and thematically related to them, giving the overall assessment of the researched field. Detailed searches for specific terms from the field of rheumatology have not been performed, as they would return interrelated results, obscuring a general assessment of the publication number. All results were limited to years 2013-2018. Data on the incidence of rheumatic diseases in Poland and the number of working rheumatologists were obtained from data published by the Central Statistical Office (Główny Urząd Statystyczny-GUS). NFZ data were used for the description of the treatment with biological drugs provided for patients with rheumatic diseases paid for from public (state) funds.

Analyzed data included public information concerning activities of the Polish Society for Rheumatology, the Ministry of Health and the Ministry of Science and Higher Education. We also used international databases of organizations such as the World Health Organization or the Organization for Economic Co-operation and Development, European Commission Database (Eurostat).

The aim of this article is to present the current state of rheumatology in Poland, including the scientific activity in this field of medicine and clinicians' involvement in the rheumatology's progress. We also present essential aspects of the system of treatment of Polish rheumatic patients.

Structure of rheumatological care: Data from the Ministry of Health report [2] for 2017 indicate that there are 2301 rheumatological hospital beds in Poland, which gives 0.6 beds per 10,000 inhabitants. For comparison, data from same sources show that there were 23,520 beds in internal medicine wards in Poland-that is, there were 6.1 beds per 10,000 inhabitants. In total, in $2017,83,069$ patients were treated in conditions of hospital stay in rheumatological wards, and 6877 patients were treated in hospital care or diagnosed in 1-day admission mode. Therefore, 21.6 patients per 10,000 inhabitants were treated in rheumatology wards [2]. The average patient stay in the rheumatology ward was calculated at 6.6 days. Data from 2010 provided by the Poland's Ministry of Health state that there were, at that time, 2279 rheumatological outpatient clinics and 955 private practices of rheumatologists registered in Poland. Most rheumatologists work in the Mazovian, Malopolskie and Silesian Voivodeships, which is not surprising as those include largest urban areas in Poland [1]. This situation greatly differentiates the number of patients per one rheumatologist in different areas of the country, and thus has an impact on the varied availability of specialist rheumatic care in particular parts of the country. However, it is important to note that patients with musculoskeletal disorders are admitted not only to rheumatologists, but often to orthopedic and neurological outpatient clinics. Therefore, these data, in terms of the total number of consultations rendered to rheumatic patients, may be incomplete. Likewise is not without significance is the fact that some patients seek help outside the state/government funding system and use private medical care [3]. It should be noted that these data are not included in the statistical lists of Ministry of Health and NFZ.

Pediatric rheumatology: In Poland, the number of specialists in pediatric rheumatology is decreasing. In 2016, their number was estimated at 69 . There are several pediatric rheumatology wards in Warsaw, Poznań, Sopot, Sosnowiec, Kraków, Łódź, and Szczecin. Some of them are interdisciplinary wards, focusing not only on rheumatic diseases, but on a treatment provided by other medical specialties-such as gastroenterology, cardiology or neurology—as well.

Board-certified rheumatologists in Poland: Based on the data from NIL, as of 30th October 2018, there are 1877 rheumatologists registered in Poland, of which 1713 are actively working in that field (to compare, at that same time there were, e.g., 4375 cardiologists and 1444 endocrinologists 
active). There are also 142 residents in rheumatology and 89 medical doctors specializing in this field of medicine outside of residence system [1]. Women predominate among the rheumatologists in Poland. What is alarming, over 30\% of rheumatologists exceeded the age of 60 years (NIL data) [1].

Postgraduate training and clinical education of rheumatologists: There are two equivalent ways in which specialization in rheumatology can be obtained. In the so-called moduletraining mode, which was introduced in 2014, 5-year internship at the rheumatological ward is combined with interim internships in various internal medicine wards $[4,5]$. The specialization in rheumatology can also be obtained as a 2-year training course for the medical doctors already specialized in internal medicine. Both training modes end with a twostage exam (a theory test and practical exam). This education system has shortened the time of specialization in rheumatology from previous 9 years ( 1 year of postgraduate internship and specialization in internal medicine [two degrees] plus sub-specialization in rheumatology) to 5 years. However, this created a risk that fewer doctors would opt for general internal specialization. The demand for rheumatologists is high, due to the fact, that rheumatic diseases, especially rheumatoid arthritis (RA), psoriatic arthritis or diseases from the spectrum of spondyloarthritis, e.g., ankylosing spondylitis (AS) occur quite often (Table 1), being a frequent cause of absenteeism and disability benefits. In Table 1 , the incidence and morbidity of rheumatic diseases in Polish population according to data from the Analysis and Strategy Department (DAiS) are presented. Batko et al. [6] presented in the cross-sectional population-based epidemiological study that prevalence of RA in Poland was 0.9\% (95\% CI 0.6-1.2\%),
$1.06 \%$ for women, $0.74 \%$ for men. The meta-analysis performed by Rudan et al. [7] estimates regional RA prevalence, e.g., $0.37 \%$ (95\% CI 0.23-0.51\%) for Eastern Mediterranean, $0.62 \%$ (95\% CI $0.47-0.77 \%$ ) for European low- and middleincome countries, $1.25 \%$ (95\% CI 0.64-1.86\%) for American low- and middle-income countries. In Greece, the RA prevalence reported in the Andrianakos et al. study in 2006 was $0.68 \%$ (95\% CI 0.51-0.85) with female to male ratio 3.3:1 [8].

Polish recommendations for the treatment of rheumatic diseases in the light of EULAR recommendations

Although EULAR recommendations are widely known and accepted in Europe as model rules of rheumatological treatment, their implementation in particular countries depends on a healthcare system organization and funding capabilities. Poland is no exception in that regard.

The current availability of the treatment with conventional synthetic modifying anti-rheumatic drugs (DMARDs) in Poland is not limited. The most widely used disease-modified anti-rheumatic drugs (DMARDs) of first choice is methotrexate, which in accordance with EULAR recommendations, is administered in rheumatoid arthritis (RA) treatment in doses of 20-25 mg per week. The dose of MTX is usually gradually increased from lower dose as $15 \mathrm{mg}$ to optimal dose. The emphasis is placed on the education of rheumatologists, who for years prescribed doses inadequately small for the disease activity. The last 2-3 years of educational efforts of main academic, clinical and scientific centers had a beneficial effect in this respect [9]. Although biological drugs are available on commercial terms, most of them are also included in the therapeutic programs developed by NFZ and the Ministry

Table 1 Incidence and morbidity of rheumatic diseases in Polish population (prepared according to DAiS-Analysis and Strategy Department Data) [3]

\begin{tabular}{lll}
\hline Disease & $\begin{array}{l}\text { Incidence registered on 100,000 } \\
\text { population }\end{array}$ & $\begin{array}{l}\text { Morbidity registered } \\
\text { on 100,000 popula- } \\
\text { tion }\end{array}$ \\
\hline Arthropathies associated with infections & 13.7 & 102.1 \\
Polyarthritis* & 284.7 & 2030.1 \\
Connective tissue diseases** & 154.5 & 357.7 \\
Muscle diseases & 21.0 & 159.3 \\
Inflammatory diseases of the fascia, tendons and soft tissues & 219.0 & 1696.8 \\
Joint diseases*** & 1538.0 & $12,299.8$ \\
Non-inflammatory diseases of the fascia, tendons and soft tissues & 1206.6 & 8217.3 \\
Disorders of mineralization and bone structure & 190.1 & 1564.2 \\
Other bone and cartilage diseases & 110.7 & 776.2 \\
Other bone, muscle and connective tissue diseases & 125.8 & 877.0 \\
Diseases of the spine & 1594.6 & $12,814.5$ \\
\hline
\end{tabular}

*Polyarthritis included diseases reported as: rheumatoid arthritis, spondyloarthritis spectrum diseases, and undifferentiated arthritis

**Connective tissue diseases as: systemic lupus erythematosus, Sjogren's syndrome, systemic sclerosis, poly- and dermatomyositis, etc.

***Joint disease including: osteoarthritis 
of Health in cooperation with representatives of the rheumatology community (Polish Society for Rheumatology). Until recently, there were five therapeutic programs enabling the treatment of aggressive forms of JIA (juvenile idiopathic arthritis), RA, ankylosing spondylitis (AS), non-radiographic spondyloarthropathy (non-radiographic $\mathrm{SpA}$ ), and psoriatic arthritis (PsA). Additionally, the program for the treatment of granulomatous with polyangiitis (GPA) and microscopic polyangitis (MPA) was introduced. Drugs available in Polish therapeutic programs in rheumatology are presented in Table 2.

We are currently awaiting the decision of authorities concerning public funding for the therapies with tofacitinib and baricitinib drugs representing a new group of targeted anti-rheumatic-modifying drugs.

The recent establishment of the program for the treatment of non-radiographic spondyloarthropathy is a major step forward in the field of rheumatology. It allows for an active treatment of patients at an early stage of the disease.

The introduction of biosimilars to the market enabled lowering of prices of biological therapies, increase the number of patients treated. In Poland, the biosimilar substitution is implemented according to recommendations for the use of biosimilars in rheumatic diseases, developed by an EULAR international task force in 2017 [10] and is considered as safe and without reduction in therapeutic efficacy $[11,12]$.

\section{The treatment of rheumatic diseases in Poland}

Rheumatoid arthritis is one of the most frequently diagnosed rheumatic diseases, the knowledge of which is relatively most widespread in the Polish society. In general, the treatment of RA with synthetic DMARDs in Poland is based on EULAR recommendations and does not differ from other European countries [12], although the decision to publicly fund targeting synthetic disease-modifying drugs in RA treatment is still pending. As for the biological therapies, abatacept has not been publicly funded in Poland, but it is available on commercial terms.

The NFZ program for the treatment of an aggressive form of RA has been introduced [13]. Participation of the patient in the program requires obtaining approval through the online system of applications called Therapeutic Program Monitoring System (SMPT; System Monitorowania Programów Terapeutycznych). Through this application, Coordination Team for Biological Treatment in Rheumatic Diseases gives consent to treatment. The program includes patients who present high disease activity, in spite of being previously treated with two DMARDs (one of them obligatorily being methotrexate)—either for 4 months in combined therapy or separately, for 4 months with each of them. The basis for the assessment of the disease

Table 2 Drugs available in Polish therapeutic programs in rheumatology

\begin{tabular}{|c|c|c|}
\hline Drug & & Indication-therapeutic program \\
\hline $\begin{array}{l}\text { Infliximab } \\
\text { Etanercept } \\
\text { Adalimumab } \\
\text { Golimumab } \\
\text { Certolizumab }\end{array}$ & Anti-TNFs & Treatment of active, aggressive rheumatoid arthritis \\
\hline Tocilizumab & Anti-IL-6 & \\
\hline Rituximab & Anti-CD20 & \\
\hline $\begin{array}{l}\text { Adalimumab, certolizumab pegol, etanercept, } \\
\text { golimumab, infliximab }\end{array}$ & Anti-TNFs & Treatment of active, aggressive PsA \\
\hline Secukinumab & Anti-IL-17A & \\
\hline $\begin{array}{l}\text { Infliximab } \\
\text { Etanercept } \\
\text { Adalimumab } \\
\text { Golimumab } \\
\text { Certolizumab }\end{array}$ & Anti-TNFs & Treatment of active AS \\
\hline Secukinumab & Anti IL-17A & \\
\hline Certolizumab & Anti-TNF & Treatment of active, non-radiographic spondyloarthropathy \\
\hline $\begin{array}{l}\text { Adalimumab (from } 3 \text { y.o) } \\
\text { Etanercept (from } 4 \text { y.o) }\end{array}$ & Anti-TNFs & JIA \\
\hline Tocilizumab & Anti-IL-6 & \\
\hline Rituximab & Anti-CD20 & GPA, MPA \\
\hline
\end{tabular}

$R A$ rheumatoid arthritis, $A S$ ankylosing spondylitis, non-radiographic spondyloarthropathy, $P s A$ psoriatic arthritis, JIA juvenile idiopathic arthritis, GPA granulomatous with polyangitis, $M P A$ microscopic polyangitis 
activity is provided with disease activity score with assessment of 28 joints (DAS28), DAS (66 swollen, 68 painful joints) or simplified disease activity index (SDAI), one of which should be evaluated in two medical examinations performed at a 1-3-month interval. High activity is confirmed, when DAS28 $\geq 5.1$; DAS 3.7; SDAI 26. The aim of the treatment is a sustained remission or low disease activity. The patients with Still's disease, secondary amyloidosis, and vasculitis are included into the program regardless of the disease activity scoring. The pool of drugs used in the program is limited. Moreover, it is not possible to use more than five biologics, including no more than two of TNF inhibitors. Only in the event of the treatment with one of TNF inhibitors being discontinued due to intolerance or side effects, the third TNF inhibitor can be used. Apart from TNF inhibitors, only other biologics used are tocilizumab and rituximab. The program is divided into stages, rituximab is usually used in the last stage only. Therapy with tocilizumab after prior treatment with rituximab is possible six month after the last dose of RTX, taking into account the potential risk and benefits.

The first-stage treatment starts with the 18-month long therapy, after which administration of the biologics is discontinued. At this stage the program dose not allow for the reduction of the dose of the biological drug or spreading the intervals between drug administrations, as it is approved in some countries. A patient can then return to the program in case of disease activity indicators increasing: DAS 28 by more than 1.2 and exceeding 3.2 , DAS by more than 1.2 and exceeding 2.4 or SDAI by more than five and exceeding 11. After returning to treatment, the time is not limited, its duration dependent only on the decision of the physician conducting such therapy.

Juvenile idiopathic arthritis (JIA) is a clinical problem not only for pediatrician rheumatologist, but also for rheumatologist for adult patients.

Patients from the age of 2 years (for adalimumab or tocilizumab therapy) from 4 years of age are eligible for the program (for etanercept therapy). The therapeutic program is constructed for all types of JIA including patients with predominant uveitis with ineffective treatment with two modifying drugs, but JIA patients with one joint involvement are not included in the therapeutic program.

The transition between young and adult patients is complicated for both medical and organizational reasons. In Poland, children's clinics can treat patients only until they reach adulthood (age of 18 years), but the current therapeutic program for biological treatment of the aggressive form of JIA allows for patients to continue therapy in the center for children for another 2 years. However, the remaining medical care must be done on the basis of an adult specialized outpatient healthcare or hospital wards, which create a difficult situation. The JIA program has also two stages. First-stage treatment lasts for 24 months or until remission is achieved [10]. The patient who has had a recurrence of an active disease, defined as the lack of persistence of the ACR Pediatric 50 improvement criteria, is included in the treatment program without re-qualification.

Although first-stage JIA treatment is longer, than in the case of RA, AS or PsA programs, the pool is more limited, which also results from the current knowledge of JIA and proper EULAR recommendations [14].

Additionally, the nature of JIA diagnosis, which-after patient reaches adulthood-can evolve into the diagnosis of RA or AS, means that, at this age, new treatment possibilities can emerge, associated with these new conditions.

Ankylosing spondylitis (AS) is relatively well-defined disease with axial and peripheral type, which may be for years undiagnosed. In rheumatological practice, a delay in diagnosis is sometimes between 5 and 10 years $[15,16]$. The delay is greater if the patient does not have an HLA B 27 antigen [16]. The treatment adheres to the EULAR recommendations, and if the conditions of persistent disease activity and bad prognostic factors are met, the patients are included in the NFZ program for the treatment of aggressive AS form with a biological drug [13]. Biological drugs with documented efficacy in the treatment of AS still remain anti-TNFs. The choice of a biological drug depends on the accompanying diseases such as uveitis, psoriatic skin lesions or the coexistence of inflammatory bowel disease. To include a patient in this therapeutic program he must have AS diagnosis established on the basis of modified New York criteria, including sacroiliitis in X-ray examination, a high disease activity defined as BASADAI score $(\geq 4)$, patients assessment of back pain on visual analogue scale (VAS $\geq 4$ ) and physician disease activity assessment (VAS $\geq 5$ ) such assessment should be performed twice with time interval of at least 4 weeks. As well as patient should be treated with biologics after an unsatisfactory response to at least two nonsteroidal anti-inflammatory drugs, each of which was used at the maximum recommended or tolerated dose for at least 4 weeks in monotherapy.

Non-radiographic axial spondyloarthropathy (nr-axSpA) at present is also possible to qualify for biological treatment patients who meet the criteria for diagnosing axial spondyloarthritis (SpA) based on ASAS criteria, without classic radiographic changes in the sacroiliac joints observed in X-ray images, with high activity in the absence of the effect of current treatment with NSAID. Typical inflammatory changes in the magnetic resonance image (MRI) should be confirmed and antigen HLA B27 should be present. For the biological treatment in the program [12], patients are qualified either based on the assessment of the disease activity (strict axial form) with the BASDAI or ASDAS index or, in the case of coexisting peripheral form of the disease, the number of affected joints and/or tendons is taken into 
account ( $\geq 5)$, along with the assessment of the disease activity by patient and doctor using the Likert scale. The disease activity should be evaluated twice, with an interval of at least 1 month. The second disease activity assessment should be performed by the doctor treating the patient and by an expert rheumatologist. At the moment, in a case of such diagnosis, certolizumab is the only biologic available in the NFZ program for non-radiographic axial SpA therapy. The decision to currently limit therapy to certolizumab was made by the health officials after taking into account the therapy costs and offers of pharmaceutical companies concerning pricing of the drugs. We may expect, however, an expansion of the pool of drugs in the future.

In psoriatic arthritis (PsA), both dermatologists and rheumatologists conduct PsA treatment, although there is presently the emphasis on patients with PsA being treated by rheumatologists, who can qualify patient for the biological therapy [12]. The biological treatment of PsA patients, with an established diagnosis based on the CASPAR criteria, includes the majority of drugs included in the EULAR and GRAPPA recommendations, with the exception from apremilast, which has registration in Poland for the treatment of psoriasis and plaque psoriasis, but is not registered for treatment of PsA and is not reimbursement in this indication. For the peripheral form of the disease, the disease activity is assessed on the basis of the Psoriatic Arthritis Response Criteria (PsARC) or DAS28, DAS and for the axial form, like the AS, with BASDAI. In the case of peripheral changes, it is important to demonstrate the ineffectiveness of 4-month therapies with methotrexate (an oral subcutaneous club form) obligatorily and one of the other specified DMARDs (leflunomide, sulfasalazine and cyclosporine). In the case of axial involvement form of the diseases, two drugs from the NSAID group have also to be found ineffective.

Granulomatous polyangiitis (GPA) and microscopic polyangiitis (MPA) are severe inflammatory diseases associated with anti-neutrophil membrane autoantibodies (c-ANCA and p-ANCA, respectively) presence. The National Health Fund founded a program of treatment ANCA associated vasculitides (GPA and MPA) with rituximab [10]. The program is aimed at patients with severe course of vasculitis, with high disease activity (BVAS $\geq 3$ points, in which one is indicated as a major symptom of active disease), presence of ANCA antibodies and with ineffectiveness or contraindications to standard inducing therapy (oral or intravenous cyclophosphamide, high doses of glucocorticosteroids). The patients with non-specific granulomatosis with vasculitis or microscopic vasculitis, regardless of the BVAS value and ANCA antibody level, which, due to the serious course of the disease, may cause a significant deterioration of healthafter obtaining separate consent of the coordinating Team. Treatment GPA and MPA appointed by the National Health Fund may also qualify to this program. Other than GPA and
MP vasculitides as Behçet disease, which is relatively rare disease in this part of Europe, is treated with immunosuppressants as azathioprine, cyclosporine $\mathrm{A}$, and glucocorticosteroids. In special cases, anti-TNFs may be considered as an off-label therapy. Interferons or apremilast are not used. Colchicine is available and may be used [17].

Systemic lupus erythematosus treatment in Poland is not different from the established standards, except for the fact, that there are no special therapeutic programs with specific medications. Belimumab is a drug very rarely used, with indications specified in the registered characteristics of the medical product.

Systemic sclerosis: The basic treatment of scleroderma does not differ from the European recommendations; however, some medicines used to treat vascular changes and pulmonary hypertension, such as riociguat [stimulator of soluble guanylate cyclase (sGC)], came into use in Poland later than in some other countries [18]. Drugs like sildenafil and mycophenolate mofetil are increasingly used. Autologous bone marrow transplants (HSCT) are also performed, however, only in a few centers, and experience is still being gathered in respect to the qualifying for the treatment and cooperation between rheumatologists and hematological centers. There are currently no programs for the management and care for patients with scleroderma after HSCT; this problem still needs to be properly addressed.

Primary Sjögren's syndrome and other connective tissue disease, such as inflammatory myositis, mixed connective tissue disease, and antiphospholipid syndrome are treated in Poland in accordance with the current recommendations and indications for which particular drugs are registered. In difficult cases, off-label therapies for rheumatic diseases might exceptionally be implemented, provided they are performed in highly specialized rheumatic centers, with an informed consent of the patient and the approval of the bioethical committee.

\section{Surgery}

The management of rheumatic diseases includes not only pharmacotherapy, but also orthopedic and neuro-orthopedic surgery. The Rheumo-orthopedic Clinic of NIGRiR is a most prominent clinical establishment in Poland, which deals mainly with surgical problems of rheumatic patients. The surgical treatment of patients with rheumatic diseases is also provided by the general orthopedic departments of other hospitals. Joint replacement (endoprosthesis) is the most often performed procedure, arthrodesis or foot and hand corrections being less frequent. Of other rheumo-orthopedic procedures, the operative treatment of instability of sacroiliac joints (sacroplasty) is one of the most important $[19,20]$. Operative synovectomy is performed less frequently than in the past currently with more 
patients being referred for a radiosynovectomy [21]. Orthopedic treatment standards in Poland do not differ from ones adopted in other European countries.

\section{Rehabilitation and balneology}

Rehabilitation is an integral part of the treatment of patients with rheumatic illnesses, mostly in cases of joint involvement, but also in such connective tissue diseases, as systemic sclerosis or polymyositis. In rheumatology centers, rehabilitation programs aimed at particular rheumatic diseases are carried out, addressing their specificity. These include a program of chest mobilization in ankylosing spondylitis, rehabilitation of the rheumatoid hand and programs for patients with muscle inflammations.

Poland, thanks to the presence of natural healing springs and favorable environmental conditions, was prone to develop balneology. There are around 45 balneology centers (hospitals and sanatoriums) with the rheumatological profile, 11 of them located in the Małopolska voivodship. Many of them-including Busko Zdrój, Ustroń, Szczawnica and Sopot—have long-standing traditions of being spa towns [22].

Patients with rheumatic diseases particularly benefit from balneotherapy, with as many as 255,870 using this complementary form of treatment in 2014 (DAiS data).

\section{The scientific activity of Polish rheumatologists}

The Polish rheumatologist is represented by the Polish Society for Rheumatology. It was first established as the Polish Society Against Rheumatism in 1930, changing the name to a current one in 1947. The first President of this society was Professor Witold Orłowski, the famous Polish internist. He was followed by professor Eleonora Reicher, the initiator of the establishing of the Institute of Rheumatology in Warsaw [23-25]. The Polish Society for Rheumatology (PTR-Polskie Towarzystwo Reumatologiczne) works closely with the Institute, which has changed the name recently to the National Institute of Geriatrics, Rheumatology and Rehabilitation as well as clinical and rheumatic centers in the education of rheumatologists and scientific activity. Polish Society for Rheumatology is one of the 45 members/societies affiliated to European League against Rheumatism (EULAR).

\section{Journals in the field of rheumatology in Poland}

Reumatologia is the journal of the highest scientific prominence of Polish periodicals concerning rheumatology. It was first published in 1963, initially as Zeszyty poświecone
Reumatologii (Journals devoted to Rheumatology ;1952-1957), than as "Postępy Reumatologii" (Advances in Rheumatology;1954-1959) and later as "Reumatologia Polska" (Polish Rheumatology;1960-1962). Currently Reumatologia is published as a English-language bi-monthly, with international Editorial Board and reviewers. It is indexed in many databases, including PMC, Scopus.

Other journals published in Poland, such as Forum Reumatologiczne (Rheumatology Forum), Reumatologia news and "Przeglad reumatologiczny" (Rheumatology Review) play educational role and are available in Polish only.

\section{Publications}

Our study analyzed all publications denoted by any of "rheumat*" keywords ("rheumatology", "rheumatic", etc.) and with the authors' affiliation associated with Poland. In Figs. 1 and 2, the number of publications from Scopus and Web of science databases was presented.

As well as in the Scopus and Web of Science databases, we searched using the earlier keywords and from which countries the articles came from.

As well as in the Scopus and Web of Science databases, we searched using earlier keywords from which countries the articles came from which was presented in Fig. 3. The countries with top numbers of affiliations match both detabases.

\section{Discussion}

On average, the Organization for Economic Co-operation and Development (OECD) countries spend 9.6\% of GDP on health care [26]. Poland occupies one of the last places allocating $6.7 \%$ of GDP for this purpose. In 2017, only Romania (5.2\%), Turkey (4.2\%), Lithuania and Latvia (both 6.3), and Luxembourg (6.1\%) had a lower percentage of funds allocated to health care. These data were presented in the paper entitled "Health at a Glance: Europe 2018" [27].

Other European countries, e.g., Germany (11.3\%), France (11.5\%) or Switzerland (12.3\%) spend much more. These numbers are important in the context of financing health care, with financing expensive therapies including biological therapies in rheumatology in particular.

In addition, the policy of pharmaceutical companies and their negotiations with the Ministry of Health in the context of reimbursement of drugs affect scope available options of rheumatic disease treatment. The problem was addressed with the creation of state-funded therapeutic programs covering treatment of patients with specific diseases requiring costly therapies. This solution, on the one hand, opened the way for the state-funded biological treatment of patients in Poland, but on the other hand introduced certain restrictions. 
Fig. 1 The number of publications on rheumatological topics from leading Polish clinicalscientific centers-data from Scopus

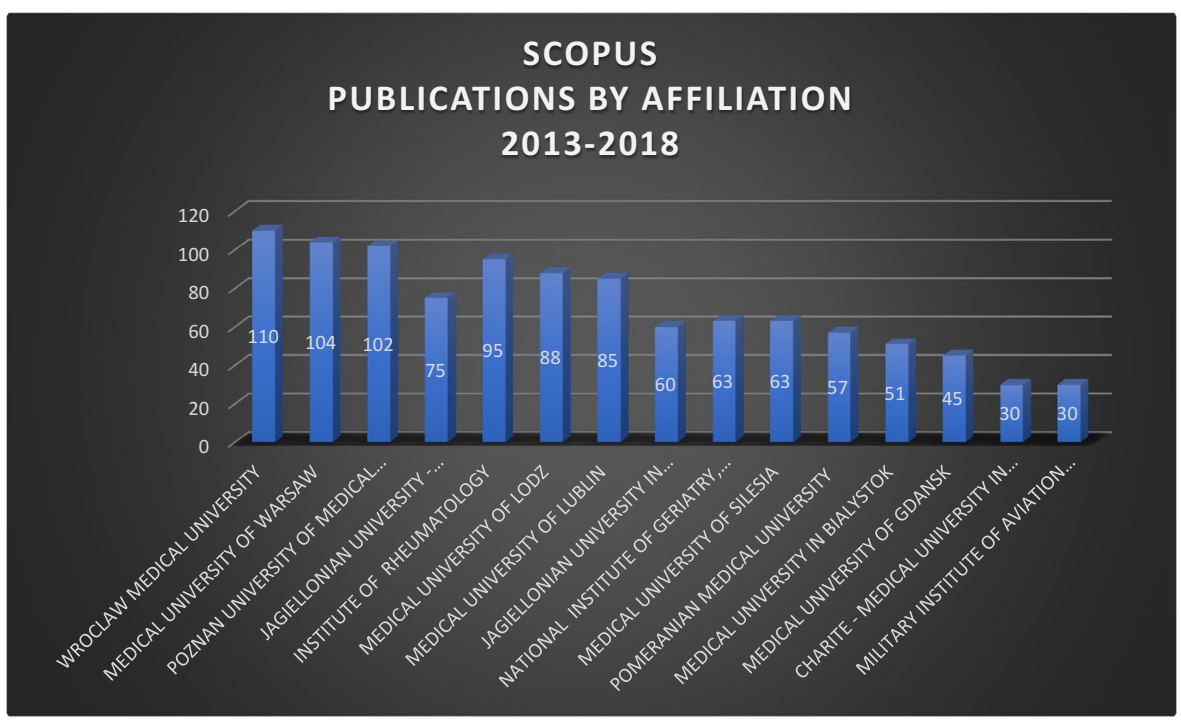

Fig. 2 The number of publications on rheumatological topics from leading Polish clinicalscientific centers-data from the Web of Science

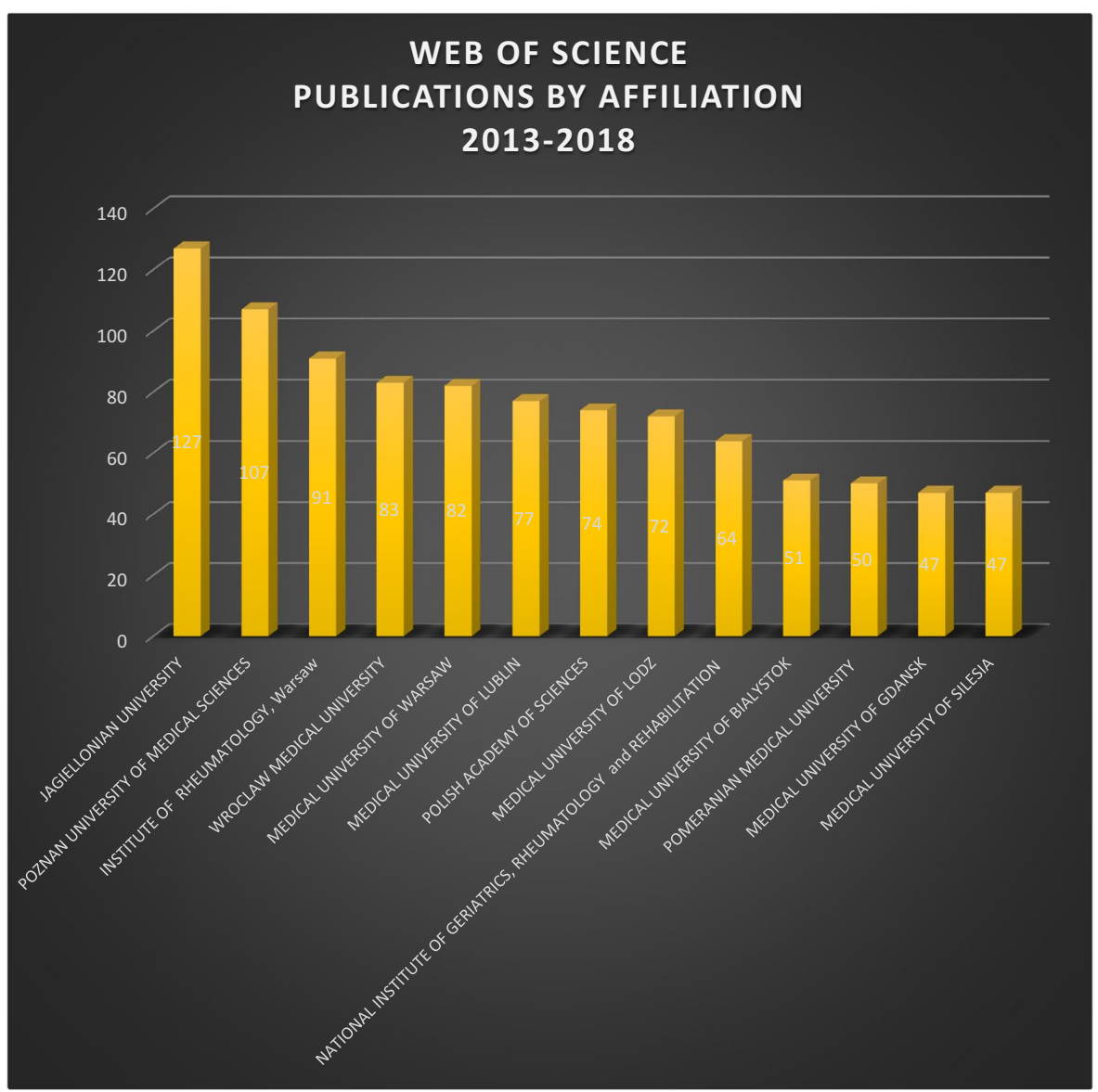

It must be noted that these restrictions in subsequent programs entries are being limited and the programs take into account EULAR recommendations.

The data on the age structure of rheumatologists are comparable with other statistical data on similar populations.
For example, the number of all physicians in the EU, aged 55 years or over, rose from $27 \%$ to $38 \%$ between years 2005 and 2016 [1]. In Poland, recent data showed that up to $27.7 \%$ still working physician are over the 65 years old [1]. Such 
Fig. 3 The number of articles by a country affiliation in Scopus and the Web of Science databases

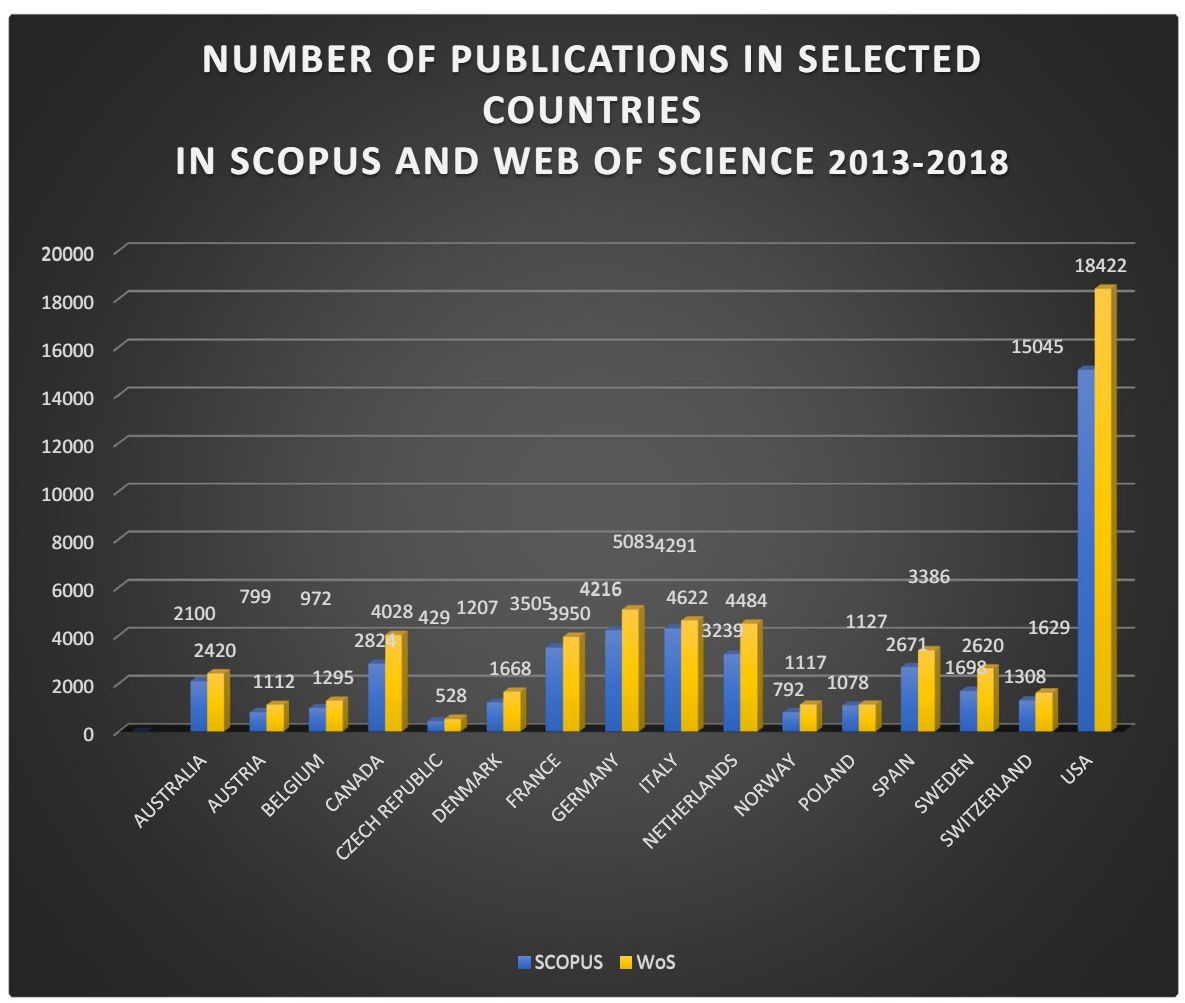

a trend is not favorable and may result in deterioration of the availability of rheumatological care in the coming years.

Women now are predominating among all physiciansthe finding reported in Denmark, Poland, Finland and Sweden. The highest percentage of women among doctors was recorded in Latvia, Estonia, Lithuania and Romania [27].

Recent data obtained from the Eurostat indicate that a ratio of the number of specialist doctors to the number of general practitioners has a tendency to increase in most of the EU countries, including Poland [27]. Such a phenomenon has recently occurred in Poland, after the introduction of new specialization rules and the outflow of doctors from Poland abroad. Thus, in the coming years GPs will constitute the most sought-after professional group. The rheumatologic pediatric care has encountered severe problems in Poland, as well as in other countries, as the number of rheumatologic pediatricians decreases all over Europe, e.g., in United Kingdom, there are currently around 60 pediatric rheumatologists only [28].

On the scientific field, the interesting "Publication Analysis 2007-2013" was presented by Kathleen Gransalke in Labtimes. In this article, Poland was on 17th place in most cited papers on field in rheumatology listed by Scimago and Thomson Reuters' Web of Science [29]. The author reported that there were 10,236 citations per 265 articles affiliated for Polish authors, which gives an average of 38.6 citations per article. It should be noted, however, that Gransalke presented data and comparisons for the authors and articles from
Europe and Israel, not from countries around the world. In our analysis, in two main databases (Scopus and Web of Science) Poland took sixth place in the number of publications on rheumatic diseases. Such data are optimistic considering the size of the Polish population and the number of rheumatologists. The interesting article by Zoltan Szekanecz et al. [30], which presents achievements and difficulties in rheumatological research in Central European countries, Austria, Croatia, Czech Republic, Hungary, Poland, Slovakia, and Slovenia, allows for a comparison of Polish rheumatology to those of the countries of the same geographical region. In the article, authors included a ranking of 84 countries concerning the number of abstracts submitted for EULAR congresses in 2015 and 2016. In those years, Poland was at 27 th and 28th place, respectively. For comparison, the ranking of other Central European countries, for the same years, was, respectively, as follows: Austria: 36th and 29th; Croatia: 48th and 53rd; Czech Republic: 35th and 32nd; Hungary: 30th and 35th; Slovakia: 51st and 62nd; Slovenia: 46th and 45th. The total acceptance rate of abstracts was $81 \%$ for Poland, which is a very good result [30]. As rankings are concerned, the Scimago Journal \& Country Rank places Poland at the second position in the field of rheumatology among Eastern European countries (with Russian Federation taking the first place) and at 23rd position among all 111 listed regions/countries [31]. The problem of the Polish medical science is undoubtedly the average salary of clinicians and researches in the clinical and scientific 
state institutions. The income is so low that the participation in foreign conferences, international scientific meetings, including EULAR conference, is very limited.

\section{Further perspectives of rheumatology in Poland}

Most important aims of today's Polish rheumatology include: the furthering of knowledge of rheumatic hazards and diseases affecting Polish population, creation of robust scientific and clinical databases and expansion of the existing network of facilities providing rheumatological diagnosis and treatment, including outpatient clinics and hospitals with rheumatological beds, with the access to diagnostics: both imaging and laboratory (especially immunological tests).

Currently, the Operational Program "Knowledge-Education-Development" (Program Wiedza Edukacja RozwójPOWER) is being implemented under the auspices of the European Union and the Ministry of Health among others in the field of rheumatology. It aims at creating a quick diagnostic pathway between primary care physicians and rheumatologists. This program is addressing the need for building the awareness - both among the patients and in the medical community - of the actual age spectrum of rheumatologic diseases. Although rheumatic diseases-in common opinion-are associated with older people only, in reality the issue concerns all age groups, especially as the diagnosis of inflammatory autoimmune rheumatic diseases moves toward the younger population. A proper knowledge, both among patients and doctors, will allow for more effective diagnosing of diseases and for an effective prophylaxis when possible. As the common knowledge is full of unverified or fake information and assumptions, the need for a proper educational base in the field of rheumatic diseases is evident $[32,33]$.

The matter of an appropriate and unified academic education in the field of rheumatology is a still unresolved issue. The need for addressing this problem becomes more apparent, as the number of medical faculties in Poland increases and some of them do not include rheumatology classes in their educational program. In such cases, rheumatology is being taught as the part of courses of other specialties, leading often to a fragmentary presentation of only selected issues. Such a situation does not allow for a comprehensive approach to rheumatology on an academic level.

\section{Conclusions}

Along with the progress of immunological knowledge and exchange of scientific information, Polish medical community improves the care for rheumatic patients in Poland, aiming at bringing it to an appropriate level. The EULAR recommendations are constantly monitored and followed on regular basis by both medical societies and public officials. Their implementation is still uncomplete, as a registration of new pharmaceuticals is a lengthy process and public funding of more expensive therapies is limited by the economic situation. However, Poland's rheumatology has made an enormous progress at all levels of functioning in recent decades, which encourages subsequent generations of doctors to choose this specialization.

Funding No funding was received for this study.

\section{Compliance with ethical standards}

Conflict of interest The authors declare no conflict of interests.

Ethical approval This article does not contain any studies with human participants or animals performed by any of the authors.

Open Access This article is distributed under the terms of the Creative Commons Attribution 4.0 International License (http://creativeco mmons.org/licenses/by/4.0/), which permits unrestricted use, distribution, and reproduction in any medium, provided you give appropriate credit to the original author(s) and the source, provide a link to the Creative Commons license, and indicate if changes were made.

\section{References}

1. Counting numbers of doctors and dentists by field and degree of specialization, including the division into doctors performing and not practicing the profession-as of 31/10/2018. https://www.nil. org.pl/_data/assets/pdf_file/0005/133961/zestawienie-nr-4.pdf. Accessed 28 November 2018

2. https://www.csioz.gov.pl/fileadmin/user_upload/Biuletyny_infor macyjny/biuletyn_2018_5c3deab703e35.pdf. Accessed 03 March 2019

3. http://www.mapypotrzebzdrowotnych.mz.gov.pl. Accessed 05 December 2018

4. Lazarewicz K, Chinoy H (2017) Rheumatology training in Poland vs. United Kingdom. Reumatologia 55(3):120-124

5. Centrum Medyczne Kształcenia (2016) Podyplomowego (CMPK) Program specjalizacji z Reumatologii. https://www.cmkp.edu.pl/ ksztalcenie/studia-specjalizacyjne-lekarzy/programy-specjaliza cjilekarskich/modulowe-programy-specjalizacji/. Accessed 3 Mar 2019

6. Batko B, Stajszczyk M, Świerkot J et al (2019) Prevalence and clinical characteristics of rheumatoid arthritis in Poland: a nationwide study. Arch Med Sci 15(1):134-140

7. Rudan I, Sidhu S, Papana A et al (2015) Prevalence of rheumatoid arthritis in low- and middle-income countries: a systematic review and analysis. J Glob Health 5(1):010409

8. Andrianakos A, Trontzas P, Christoyannis F, for the ESORDIG study group, et al (2006) Prevalence and management of rheumatoid arthritis in the general population of Greece-the ESORDIG study, Rheumatology 45(12):1549-1554

9. Świerkot J, Batko B, Wiland P, Jędrzejewski M, Stajszczyk M (2018) Methotrexate treatment for rheumatoid arthritis in Poland: Retrospective analysis of patients in routine clinical practice. Reumatologia 56(1):3-9 
10. Kay J, Schoels MM, Dörner T et al (2018) Consensus-based recommendations for the use of biosimilars to treat rheumatological diseases. Ann Rheum Dis 77:165-174

11. Wiland P, Batko B, Brzosko M et al (2018) Biosimilar switching - current state of knowledge. Reumatologia 56(4):234-242. https://doi.org/10.5114/reum.2018.77975

12. Smolen JS, Landewé R, Bijlsma J et al (2017) EULAR recommendations for the management of rheumatoid arthritis with synthetic and biological disease-modifying antirheumatic drugs: 2016 update. Ann Rheum Dis 76:960-977

13. https://www.gov.pl/web/zdrowie/choroby-nieonkologiczne. Accessed 10 January 2018

14. Foster HE, Minden K, Clemente D et al (2017) EULAR/PReS standards and recommendations for the transitional care of young people with juvenile-onset rheumatic diseases. Ann Rheum Dis 76:639-646

15. Dincer U, Cakar E, Kiralp MZ, Dursun H (2008) Diagnosis delay in patients with ankylosing spondylitis: possible reasons and proposals for new diagnostic criteria. Clin Rheumatol 27(4):457-462

16. Fallahi S, Jamshidi AR (2015) Diagnostic delay in ankylosing spondylitis: related factors and prognostic outcomes. Arch Rheumatol 31(1):24-30

17. Hatemi G, Christensen R, Bang D et al (2018) 2018 update of the EULAR recommendations for the management of Behçet's syndrome. Ann Rheum Dis 77:808-818

18. Kowal-Bielecka O, Fransen J, Avouac J et al (2017) Update of EULAR recommendations for the treatment of systemic sclerosis. Ann Rheum 76(8):1327-1339

19. Gasik R, Kamińska-Tchórzewska E (2013) Osteoporosis fracture of sacral bone treated with bone cement-sacroplasty. Reumatologia 51(4):304-307

20. Zaidi HA, Montoure AJ, Dickman CA (2015) Surgical and clinical efficacy of sacroiliac joint fusion: a systematic review of the literature. J Neurosurg Spine 23:59-66

21. Chojnowski M, Felis-Giemza A, Kobylecka M (2016) Radionuclide synovectomy - essentials for rheumatologists. Reumatologia 54(3):108-116

22. Dobrzyński D, Boguszewska-Czubara A, Sugimori K (2018) Hydrogeochemical and biomedical insights into germanium potential of curative waters: a case study of health resorts in the Sudetes Mountains (Poland). Environ Geochem Health 40(4):1355-1375
23. Brzozowski R (2007) Wspomnienie o profesorze Witoldzie Orłowskim. Postępy Nauk Med 2-3:99-104

24. Maślińska M (2011) She started everything: tribute to Professor Eleonora Reicher on the 60th anniversary of the Institute of Rheumatology. Reumatologia 49(5):315-320

25. Sadowska-Wróblewska M (1973) Prof. Dr. med. Eleonora Reicher Reumatologia 11:201-203

26. OECD/EU (2018) Health at a Glance: Europe 2018: State of Health in the EU Cycle. OECD Publishing, Paris. https://doi. org/10.1787/health_glance_eur-2018-en

27. Eurostat http://ec.europa.eu/eurostat/product?code=hlth_rs_ phys\&language $=$ en $\&$ mode $=$ view. Accessed 19 December 2018

28. Al Maini M, Adelowo F, Al Saleh J et al (2014) The global challenges and opportunities in the practice of rheumatology: white paper by the World Forum on Rheumatic and Musculoskeletal Diseases. Clin Rheumatol 34(5):819-829

29. Gransalke K (2017) Publication analysis 2013-2017. Rheumatology Lab Times 1:32-34

30. Szekanecz Z, Anic B, Héjj G et al (2017) Opportunities and challenges in rheumatology research in Central Europe. Arthritis Res Ther 19(1):196. https://doi.org/10.1186/s13075-017-1368-z Published 2017 Sep 4.

31. https://www.scimagojr.com/countryrank.php?category $=2745 \&$ a rea $=2700$ \&year $=2017$. Accessed 14 January 2018

32. Szpakowski R, Maślińska M, Dykowska G, Zając P (2015) Analysis of information on rheumatology from a selected Internet forum in the context of the need for telemedicine solutions. Reumatologia 53(5):260-267. https://doi.org/10.5114/reum.2015.55829

33. Severo M, Gaio R, Lucas R, Barros H (2010) Assessment of the general public's knowledge about rheumatic diseases: evidence from a Portuguese population-based survey. BMC Musculoskelet Disord 11:211. https://doi.org/10.1186/1471-2474-11-211 Published 2010 Sep 16.

Publisher's Note Springer Nature remains neutral with regard to jurisdictional claims in published maps and institutional affiliations. 